\title{
ANALISIS PENGARUH LINGKUNGAN TERHADAP MODAL INTELEKTUAL ORGANISASI
}

\author{
Engkos Achmad Kuncoro ${ }^{1}$
}

\begin{abstract}
The research purpose was to describe and analyze how far the influence of external and organization environment as independent variable to individual intellectual competence transformation process to become organization intellectual capital, as dependent variable. The research method used in this research is the survey method with quantitative approach. Research result show that exogen variable of External Environment LE) has influence of 0.565 or $56.5 \%$, and 0,661 or $66,1 \%$ of variable Organization Climate (IKO) to Intellectual Competence (KII) as intervening variable. Meanwhile Intervening KII variable has influence of 0.609 or $60.9 \%$ on Intellectual Capital (INO) as endogen variable.
\end{abstract}

Keywords: external and organization environment, organization intellectual capital

\begin{abstract}
ABSTRAK
Tujuan penelitian adalah mendeskripsikan dan menganalisis seberapa jauh pengaruh lingkungan (eksternal dan iklim organisasi) sebagai variabel independen pada proses transformasi kompetensi intelektual individu menjadi modal intelektual organisasi, sebagai variabel dependen. Metode penelitian yang digunakan dalam penelitian ini adalah metode survei dengan pendekatan kuantitatif. Hasil penelitian menunjukkan bahwa variabel eksogen Lingkungan Eksternal (LE) memiliki pengaruh sebesar 0.565 atau 56.5\% terhadap variabel intervening Kompetensi Intelektual (KII), variabel eksogen Iklim Organisasi (IKO) sebesar 0.661 atau 66.1\% terhadap Variabel Intervening KII, dan variabel Intervaning KII memiliki pengaruh sebesar 0.609 atau 60.9\% terhadap variabel endogen Modal Inteletual Individu (INO).
\end{abstract}

Kata kunci: lingkungan eksternal dan organisasi, modal intelektual organisasi

\footnotetext{
${ }^{1}$ Jurusan Manajemen, Universitas Bina Nusantara, Jl. K.H. Syahdan No. 9, Palmerah, Jakarta Barat 11480, eak@binus.ac.id
} 


\section{PENDAHULUAN}

Sebagaimana diketahui bahwa persaingan yang dihadapi oleh Perguruan Tinggi Swasta (PTS) makin lama makin ketat, hal itu karena masing-masing PTS berusaha menarik para pelanggan masuk dalam lingkungannya. PTS tidak hanya ingin survive dengan memperoleh jumlah mahasiswa yang cukup dan bermutu tetapi juga PTS ingin mengembangkan dirinya menjadi PTS yang mampu menghasilkan lulusan yang bermutu agar dapat diserap oleh lapangan kerja, baik di dalam negeri maupun di luar negeri. Persaingan yang kini dihadapi oleh perguruan tinggi, tidak terkecuali Universitas Bina Nusantara sebagai salah satu perguruan tinggi swasta di Jakarta Barat, adalah masalah mutu. Mutu, tercakup di dalamnya ialah mutu mahasiswa, dosen, karyawan, fasilitas (gedung, peralatan, dan perlengkapan pendidikan), pelayanan, sistem yang digunakan, dan proses belajar mengajar. Jika mutu komponen pendidikan baik maka diharapkan mutu lulusan juga baik. Mutu lulusan yang baik akan mudah diserap oleh pasar kerja.

Salah satu indikator bahwa PTS mampu bersaing dan dapat memenangkan persaingan ialah PTS itu diminati oleh masyarakat, pelanggan, dan pengguna lulusannya. Minat itu tidak hanya terhadap lulusan PTS tetapi juga minat untuk memasuki PTS serta minat untuk memberikan kepercayaan kepada PTS mengadakan kerja sama dan mengadakan hubungan kerja. Untuk dapat diminati, perguruan tinggi harus bermutu dan memiliki reputasi yang baik. Bermutu artinya memenuhi kriteria permintaan masyarakat, tidak hanya terbatas pada mutu produk dalam dunia pendidikan, termasuk yang penting adalah mutu proses.

Untuk mencapai mutu yang diinginkan dalam menghadapi persaingan, PTS harus memiliki modal, selain modal fisik, terutama harus memiliki modal pengetahuan yang cukup. Modal pengetahuan itu berasal dari seluruh anggota PTS, terutama dosen, dalam bentuk kompetensi intelektual guna melaksanakan proses pembelajaran dan proses pelayanan kepada para pelanggannya (mahasiswa, orang tua, instansi bisnis, dan pemerintahan). Dengan demikian, penting bagi PTS untuk dapat mentransformasikan kompetensi intelektual yang dimiliki oleh dosen menjadi modal intelektual PTS (organisasi) yang dapat digunakan untuk menghadapai para pesaing. Bertitik tolak dari kondisi tersebut maka penelitian ini dilakukan. Sebagai unit analisis, dipilih Fakultas Ekonomi sebagai salah fakultas di Universitas Bina Nusantara. Fakultas Ekonomi UBINUS berdiri tahun 1996 dan per semester ganjil 2007 memiliki jumlah dosen Home Base sebanyak 84 orang, Part Time sebanyak 88 orang sehingga total menjadi 172 orang.

Tujuan penelitian untuk adalah mengindentifikasikan dimensi lingkungan eksternal organisasi perguruan tinggi swasta, khususnya di Universitas Bina Nusantara; Untuk mengetahui seberapa signifikan pengaruh kompetensi intelektual individu dosen terhadap modal intelektual organisasi; Untuk menguji secara empirik seberapa signifikan pengaruh lingkungan eksternal persaingan terhadap kompetensi intelektual individu menjadi modal intelektual organisasi; Untuk mengetahui adakah perbedaan pengaruh jabatan akademik dosen, tingkat pendidikan dosen, dan pengalaman kerja dosen terhadap kompetensi intelektual dosen menjadi modal intelektual organisasi. 


\section{TINJAUAN PUSTAKA}

Pendidikan adalah proses pengubahan sikap dan tata laku seseorang atau kelompok orang dalam usaha mendewasakan manusia melalui upaya pengajaran dan latihan (Kamus besar Bahasa Indonesia, 1996:204). Sementara, dalam Undang-undang No. 20 tahun 2003 tentang Sistem Pendidikan Nasional, Pasal 1, ayat 1, menyebutkan:

"Pendidikan adalah usaha sadar dan terencana untuk mewujudkan suasana belajar dan proses pembelajaran agar peserta didik secara aktif mengembangkan potensi dirinya untuk memiliki kekuatan spiritual keagamaan, pengembangan diri, kepribadian, kecerdasan, akhlak mulia, serta keterampilan yang diperlukan dirinya, masyarakat, bangsa dan negara”.

Dengan demikian, pendidikan adalah suatu proses pengembangan manusia hingga manusia itu tumbuh optimal sebagai manusia yang beradab tinggi. Pendidikan dengan berbagai programnya mempunyai peran penting dalam proses memperoleh dan meningkatkan mutu kemampuan profesional individu, melalui pendidikan, seseorang dipersiapkan untuk memiliki bekal agar siap tahu, mengenal dan mengembangkan metode berfikir secara sistematik sehingga mampu memecahkan masalah yang akan dihadapi dalam kehidupan di kemudian hari.

Masalah yang dihadapi Perguruan Tinggi (PT) sekarang ini secara umum adalah Pemerintah tengah reorientasi regulasi di bidang pendidikan secara total, sarana dan pra sarana PT masih belum merata, hasil akreditasi ternyata masih belum mampu mencerminkan keadaan yang sebenarnya (baik bagi PT maupun alumni), masih terdapat dosen dan mahasiswa yang terlibat proses belajar mengajar tidak dengan konsep sebagaimana semestinya (bahkan cenderung melihatnya sebagai proses entertain saja), dan laju pembiayaan pendidikan yang terus meningkat. Pasar Global menuntut pengembangan kurikulum dan silabus termasuk peran dosen dan manajemen PT. PT harus menjadi daya penggerak yang dinamis bagi proses modernisasi yang dapat mengusahakan penemuan arah modernisasi menuju pembangunan masyarakat masa depan. Pengembangan sistem ditujukan kepada penegakan suatu sistem pendidikan tinggi di Indonesia secara menyeluruh.

Manusia sebagai makhluk sosial memerlukan organisasi dalam rangka interaksinya dengan sesama manusia atau dengan lingkungan. Hampir setiap sendi kehidupan tidak lepas dari organisasi, baik yang sifatnya formal maupun infornal. Akan tetapi, semua organisasi baik formal maupun informal, disatukan dan dipertahankan kesatuannya oleh kelompok orang yang melihat bahwa ada manfaat untuk bekerja sama ke arah sasaran yang sama. Menurut Stoner (1995), elemen yang sangat mendasar dalam organisasi apapun adalah sasaran (goals) atau tujuan. Semua organisasi juga mempunyai beberapa program atau metode untuk mencapai sasaran, yaitu rencana, karena tanpa rencana yang harus dikerjakan, kemungkinan besar tidak ada organisasi yang bertindak efektif. 
Untuk mencapai sasaran, organisasi harus memiliki dan mengalokasikan sumber daya yang perlu. Semua organisasi tergantung pada organisasi lain untuk sumber daya yang mereka perlukan. Sebuah perguruan tinggi tidak dapat menjalankan proses pembelajaran tanpa dukungan peralatan yang diperlukan, dan peralatan itu harus dibuat oleh organisasi lain. Semua organisasi mempunyai orang yang bertanggung jawab terhadap organisasi dalam mencapai sasarannya, orang itu disebut manager, dan manager dalam mengelola organisasi menjalankan fungsi manajemen. Menurut Jones (dalam Moedjadi, 2005), organisasi adalah suatu alat yang digunakan oleh manusia, baik secara individu maupun kelompok, untuk mencapai tujuan. Suatu organisasi mengandung kumpulan pengetahuan, nilai, dan pandangan orang yang secara sadar (dan kadang tidak sadar) berusaha untuk memperoleh sesuatu yang mereka inginkan atau yang berharga.
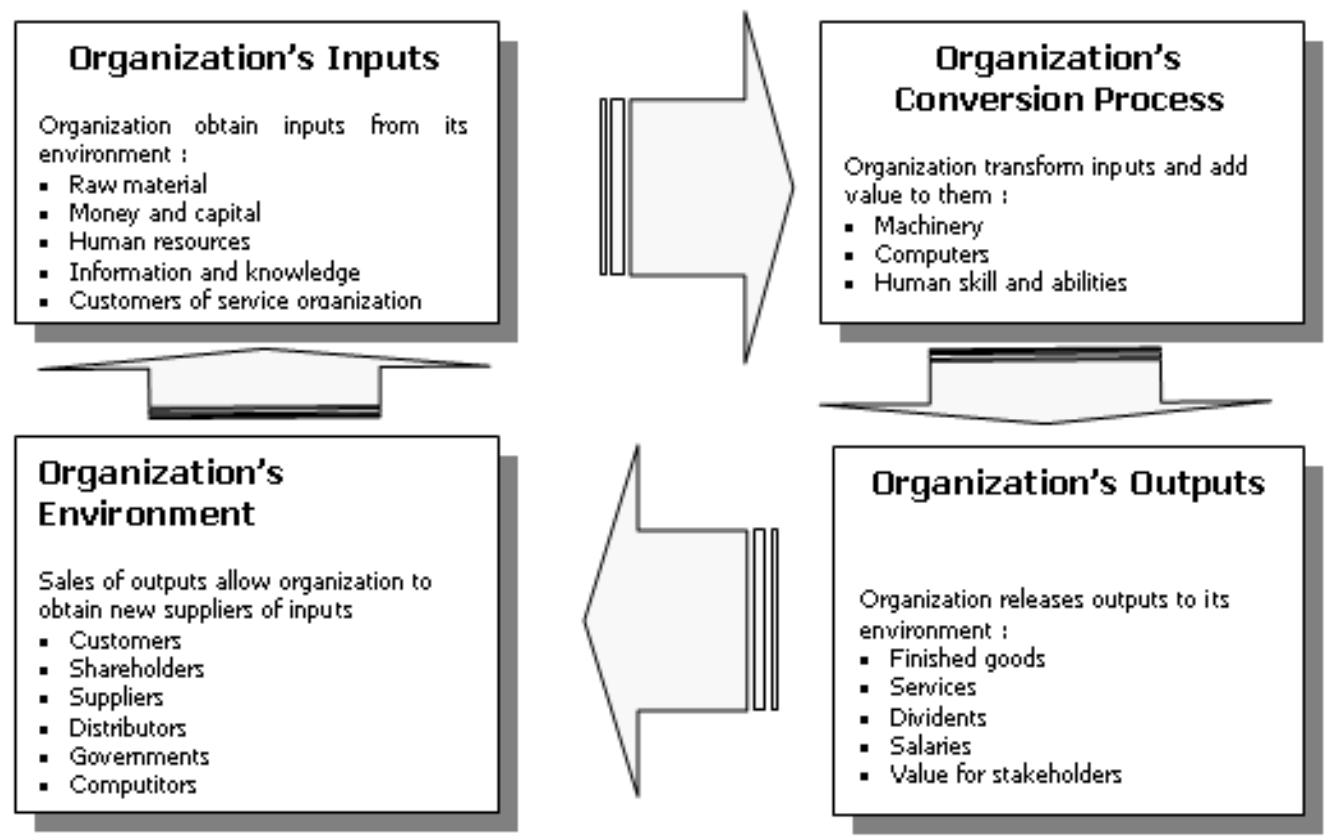

Organization's Outputs

Organization releases outputs to its

environment :

- Finished goods

- Services

- Dividents

- Salaries

- Value for stakeholders

Sumber: Jones (dalam Moedjadi, 2005)

Gambar 1 Bagaimana Suatu Organisasi Menciptakan Nilai

Suatu organisasi mengandung kumpulan pengetahuan, nilai, dan pandangan orang secara sadar, berusaha untuk memperoleh sesuatu yang mereka inginkan atau yang berharga. Suatu organisasi adalah suatu respon dan alat untuk menciptakan nilai yang memberikan kepuasan kepada kebutuhan manusia.

Lingkungan eksternal adalah lingkungan yang berada di luar sistem organisasi dan karena itu tidak dapat dikendalikan oleh organisasi. Bagi organisasi pendidikan, lingkungan eksternal, meliputi ekonomi, politik, keamanan, kebudayaan, agama, kebijakan pemerintah, norma dan nilai, taraf hidup, teknologi, demografi, globalisasi, persaingan, dan lainnya. 
Kolb et al. (1991) mengukur iklim menurut persepsi para anggotanya melalui perbedaan antara iklim yang ada dan yang diharapkan dengan tujuh dimensi, diantaranya yang digunakan dalam penelitian ini, yaitu imbalan/penghargaan, semangat kelompok/hubungan kerja, kejelasan kerja, dan kepemimpinan. Sesuai dengan kepustakaan dan kajian penelitian tentang iklim organisasi, iklim organisasi dapat berperan sebagai variabel independen dan dependen maupun intervening serta variabel penengah (moderator).

Menurut Spencer dan Spencer (1993:13) motif (motive), watak (trait), dan konsep diri (self concept), serta pengetahuan (knowledge) dapat menggambarkan karakteristik individu yang mana kemauan berakibat pada hasil kinerja seperti digambarkan sebagai berikut.

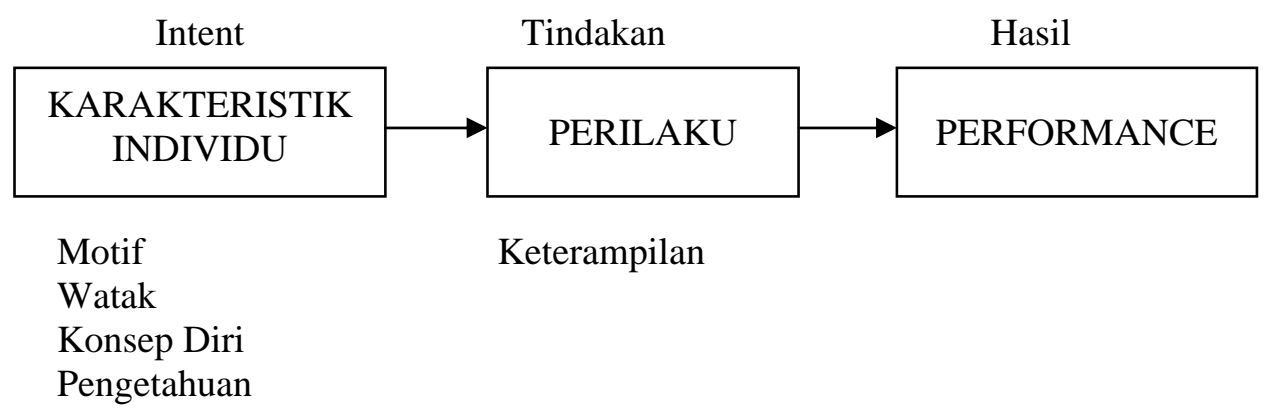

Sumber: Spencer dan Spencer, 1993

Gambar 2 Model Hubungan Pengaruh Karakteristik Individu terhadap Kinerja Pekerjaan

Spenser dan Spenser (1993) membagi kompetensi individu menjadi enam kelompok, dimana masing-masing kelompok tersebut terdiri dari lima sampai enam kompetensi, kelompok kompetensi ini diantaranya adalah sebagai berikut: (1) Semangat untuk berprestasi dan bertindak (achievement and action) yang mencakup kompetensi: orientasi prestasi (achievement orientation), penilaian terhadap kerapian, mutu, dan ketelitian (concern for order); Inisiatif (initiative), yaitu bertindak melebihi yang dibutuhkan atau diharapkan. (2) Kemampuan pelayanan (helving and human services) yang mencakup kompetensi: empati (interpersonal understanding), orientasi pelayanan dan kepuasan pelayanan atau kepuasaan pelanggan (customer services orientation). (3) Kemampuan mempengaruhi orang lain (the impact an influence) yang mencakup kompetensi: pengaruh strategis mendukung dan mempengaruhi (impact an influence), kesadaran berorganisasi (organization awarenes), membangun hubungan kerja (relation building). (4) Kemampuan manajerial (managerial) yang mencakup kompetensi: kemampuan memberi dukungan (develoving others), keberanian memberi perintah dan memanfaatkan kekuasaan jabatan (directiveness assertivenes an news of posisitional power), kerja kelompok dan kerja sama (teamwork an cooperation), kepemimpinan kelompok (team leadership). (5) Daya pikir atau kemampuan keahlian (cognitif) yang 
mencakup kompetensi: berpikir analistis (analitical thinking), berpikir konseptual (conceptual thinking), keahlian teknis (exspertise). (6) Efektivitas individu (personal effectiveness) yang mencakup kompetensi: pengendalian diri ( self control), kepercayaan diri (self confidence), fleksibilitas (flexsibility), dan komitmen pada organisasi.

\section{Modal Intelektual Organisasi}

Stewart (dalam Moedjadi, 2005:96), modal intelektual adalah jumlah semua hal yang diketahui dan diberikan oleh semua orang dalam perusahaan/organisasi yang memberikan keunggulan bersaing. Sifat modal intelektual tidak berwujud karena itu diistilahkan sebagai modal maya. Modal intelektual didefinisikan sebagai materi intelektual, pengetahuan, informasi, hak pemilikan intelektual, pengetahuan yang dapat digunakan untuk menciptakan kekayaan. Termasuk dalam modal intelektual ialah pengetahuan, tenaga kerja, institusi tim ahli atau keahlian tenaga kerja yang menghasilkan seribu macam alternatif untuk meningkatkan kemampuan organisasi.

Menurut Hidayat (2001), dimensi modal intelektual terbagi atas: a) Modal intelektual internal (perilaku belajar dan berinovasi), yaitu kebiasaan dan keberanian para anggota organisasi untuk berbagi ide, pendapat, nasihat, serta semangat untuk terus belajar memperdalam dan memperluas pengetahuan dan keahlian baru; b) Modal intelektual eksternal, yaitu semangat untuk meningkatkan modal struktural organisasi, teknologi inti yang strategik, quick responses.

Lebih jauh Stewart (dalam Moejadi, 2005:101) menyatakan bahwa perusahaan yang menguasai pengetahuan adalah perusahaan yang menang dalam persaingan dalam Abad ke-21. Hal itu karena pengetahuan merupakan faktor yang sangat penting dalam produksi dan aset pengetahuan merupakan produsen yang kuat atas kesehatan organisasi. Organisasi dan kepemimpinan yang menguasai pengetahuan akan daya saing yang tinggi.

\section{METODE PENELITIAN}

Penelitian ini dimaksudkan untuk mengungkap gambaran tentang pengaruh lingkungan eksternal dan iklim organisasi terhadap proses transformasi kompetensi intelektual individu dosen FE UBINUS menjadi modal intelektual organisasi FE UBINUS (Gambar 3). Sasaran penelitian ini adalah dosen Home Base dan part time Fakultas Ekonomi, Universitas Bina Nusantara yang dipilih berdasarkan sampel. Sebagai alat pengumpul data digunakan kuesioner yang dilengkapi dengan studi dokumen sedangkan metode yang dipilih adalah metode survey dengan pendekatan kuantitatif. 
Untuk penentuan sampel atau responden penelitian dilakukan dengan rumus berikut (Riduwan \& Kuncoro, 2007).

$$
\begin{aligned}
\mathrm{n} & =\frac{\mathrm{N}}{\mathrm{Nd}^{2}+1} \\
\text { Keterangan : } \mathrm{n} & =\text { Jumlah sampel } \\
\mathrm{N} & =\text { Jumlah populasi } \\
\mathrm{d}^{2} & =\text { Presisi yang ditetapkan }
\end{aligned}
$$

Berdasarkan data pada Fakultas Ekonomi UBINUS per semester ganjil 2007 jumlah dosen sebanyak 172 orang, dengan tingkat kesalahan 6\% maka diperoleh hasilnya sampelnya menjadi: 106 orang dosen.

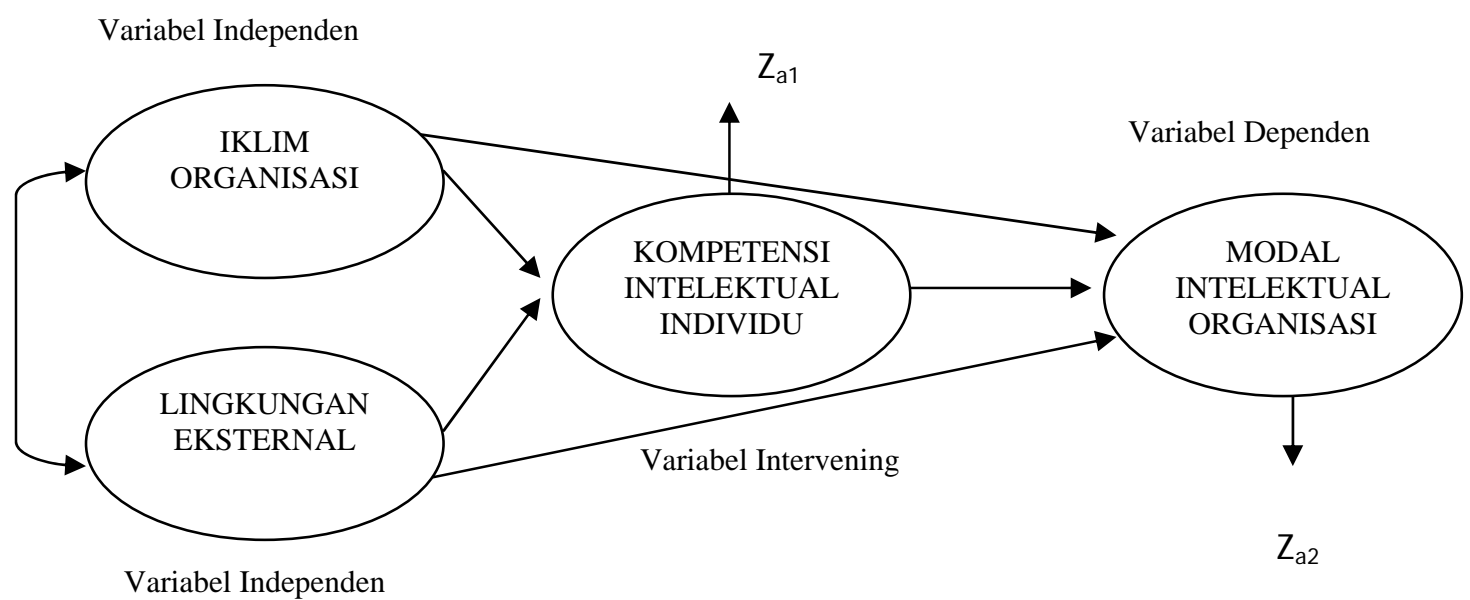

Gambar 3 Model Dasar Penelitian

Tabel 1 Kisi Pernyataan Variabel Dependent (X1 dan X2)

\begin{tabular}{lll}
\hline \multicolumn{1}{c}{ Variabel } & \multicolumn{1}{c}{ Dimensi } & \multicolumn{1}{c}{ Indikator } \\
\hline & 1. Persaingan dalam harga atau biaya pendidikan & $\begin{array}{l}\text { Jumlah biaya pendidikan } \\
\text { Sistem pembayaran biaya pendidikan }\end{array}$ \\
\cline { 2 - 3 } Lingkungan & 2. Persaingan dalam kualitas atau mutu pelayanan & $\begin{array}{l}\text { Peraturan-peraturan biaya perkuliahan } \\
\text { Sistem informasi akademik } \\
\text { Program studi }\end{array}$ \\
\cline { 2 - 3 } & 3. Persaingan dalam mutu dosen & $\begin{array}{l}\text { Mutu dosen } \\
\text { Mutu fasilitas } \\
\text { Mutu lulusan }\end{array}$ \\
\cline { 2 - 3 } & 4. Persaingan dalam promosi & $\begin{array}{l}\text { Tingkat frekuensi } \\
\text { Jenis promosi }\end{array}$ \\
\hline
\end{tabular}




\begin{tabular}{|c|c|c|}
\hline Variabel & Dimensi & Indikator \\
\hline \multirow{6}{*}{$\begin{array}{l}\text { Iklim Organisasi } \\
\text { (IKO) }\end{array}$} & \multirow{3}{*}{ 1. Kepemimpinan } & Visioner \\
\hline & & Kreativitas \\
\hline & & Mentor (Coaching) \\
\hline & 2. Sistem Penghargaan & $\begin{array}{l}\text { Intrinsic Reward } \\
\text { Extrinsic Reward } \\
\text { Carrier Planning }\end{array}$ \\
\hline & 3. Semangat Kerja Kelompok & $\begin{array}{l}\text { Hubungan kerja sama antar dosen } \\
\text { Hubungan kerja dalam penelitian }\end{array}$ \\
\hline & 4. Kejelasan Aturan & $\begin{array}{l}\text { Relevansi aturan } \\
\text { Birokrasi sederhana }\end{array}$ \\
\hline
\end{tabular}

Sumber: Senge, 1990

Tabel 2 Kisi Pernyataan Variabel Intervening (Y3)

Variabel

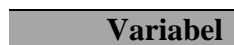

Intelektual Individu

(KII)

\section{Dimensi}

1. Kemampuan berprestasi dan keahlian professional

2. Kemampuan untuk membantu orang lain

3. Kemampuan kognitif

4. Kemampuan mempengaruhi orang lain
Indikator

Berorientasi pada mutu dan ketepatan Mencari Informasi

Beorientasi pada kepuasan pelanggan

Empati

Kemampuan berfikir analitis Kemampuan berfikir konsep Kemampuan atau keinginan untuk meyakinkan, mempengaruhi, dan memberikan kesan kepada orang lain agar memberikan dukungan kepada dirinya

5. Kemampuan manajerial

Kemampuan dan kemauan untuk memimpin

6. Kematangan pribadi

Komitmen pada organisasi

Sumber: (Spencer \& Spencer, 1993 dan diolah penulis) 
Tabel 3 Kisi Pernyataan Variabel Independent (Y4)

\begin{tabular}{|c|c|c|}
\hline Variabel & Dimensi & Indikator \\
\hline \multirow{10}{*}{$\begin{array}{c}\text { Intelektual } \\
\text { Organisasi (INO) }\end{array}$} & \multirow{4}{*}{ 1. Belajar dan berinovasi } & Berprestasi \\
\hline & & Semangat berinovasi \\
\hline & & Berkomunikasi \\
\hline & & Semangat belajar \\
\hline & \multirow{5}{*}{ 2. Modal struktur dan teknologi } & $\begin{array}{l}\text { Peta pengetahuan dan keahlian anggota } \\
\text { organisasi }\end{array}$ \\
\hline & & Memahami profil pesaing dan pelanggan \\
\hline & & $\begin{array}{l}\text { Pengakuan atas kompetensi } \\
\text { intelektualnya }\end{array}$ \\
\hline & & Pengakuan atas keunggulan produk \\
\hline & & $\begin{array}{l}\text { Mampu belajar dari pengalaman } \\
\text { kesalahan }\end{array}$ \\
\hline & 3. Cepat tanggap & $\begin{array}{l}\text { Kemampuan dan kemauan menanggapi } \\
\text { keluhan pelanggan }\end{array}$ \\
\hline
\end{tabular}

Sumber: (Spencer \& Spencer, 1993 dan diolah penulis)

\section{HASIL DAN ANALISIS PENELITIAN}

\section{Penilaian Model FIT}

Dalam konsep dasar Structural Equation Modeling (SEM) terdapat tujuh prosedur dalam membuat suatu model (LISREL, 2006), antara lain Spesifikasi Model (Model Specification), Identifikasi (Identification), Estimasi (Estimation), Uji kecocokan (Testing Fit) atau penilaian Model Fit, Kecocokan keseluruhan model (overall model Fit), Kecocokan model pengukuran (measurement model Fit) yang terdiri dari Validitas dan Realibilitas, Kecocokan model structural (structural model Fit), dan Respesifikasi (Respesification) atau modifikasi model.

\section{Spesifikasi Model (Model Specification)}

Berdasarkan teori yang telah dipaparkan sebelumnya, dihipotesiskan bahwa terdapat hubungan dan pengaruh antara variabel eksogen (Iklim Organisasi $=\mathbf{I K O}$ dan Lingkungan Eksternal $=\mathbf{L E})$ dan variabel latennya $($ Model intelektual Organisasi $=\mathbf{I N O})$ dengan variabel antara/interveningnya (Kompetensi intelektual Individu $=\mathbf{K I I})$. Dari Gambar 4 (Path Diagram Awal) dapat diindetifikasikan sebagai berikut: Variabel LE (Lingkungan Eksternal) diukur dengan instrument yang terdiri dari 10 item pernyataan, dimulai dari A1 - A10; Variabel IKO (Iklim Organisasi) diukur dengan instrument yang terdiri dari 10 item pernyataan, dimulai dari B1 - B10; Variabel KII (Kompetensi Intelektual Individu) diukur dengan instrument yang terdiri dari 10 item pernyataaan, dimulai dari C1 - C10; Variabel INO (Intelektual Organisasi) diukur dengan instrument yang terdiri dari 10 item pernyataan, dimulai dari D1 - D10 (Gambar 4). 


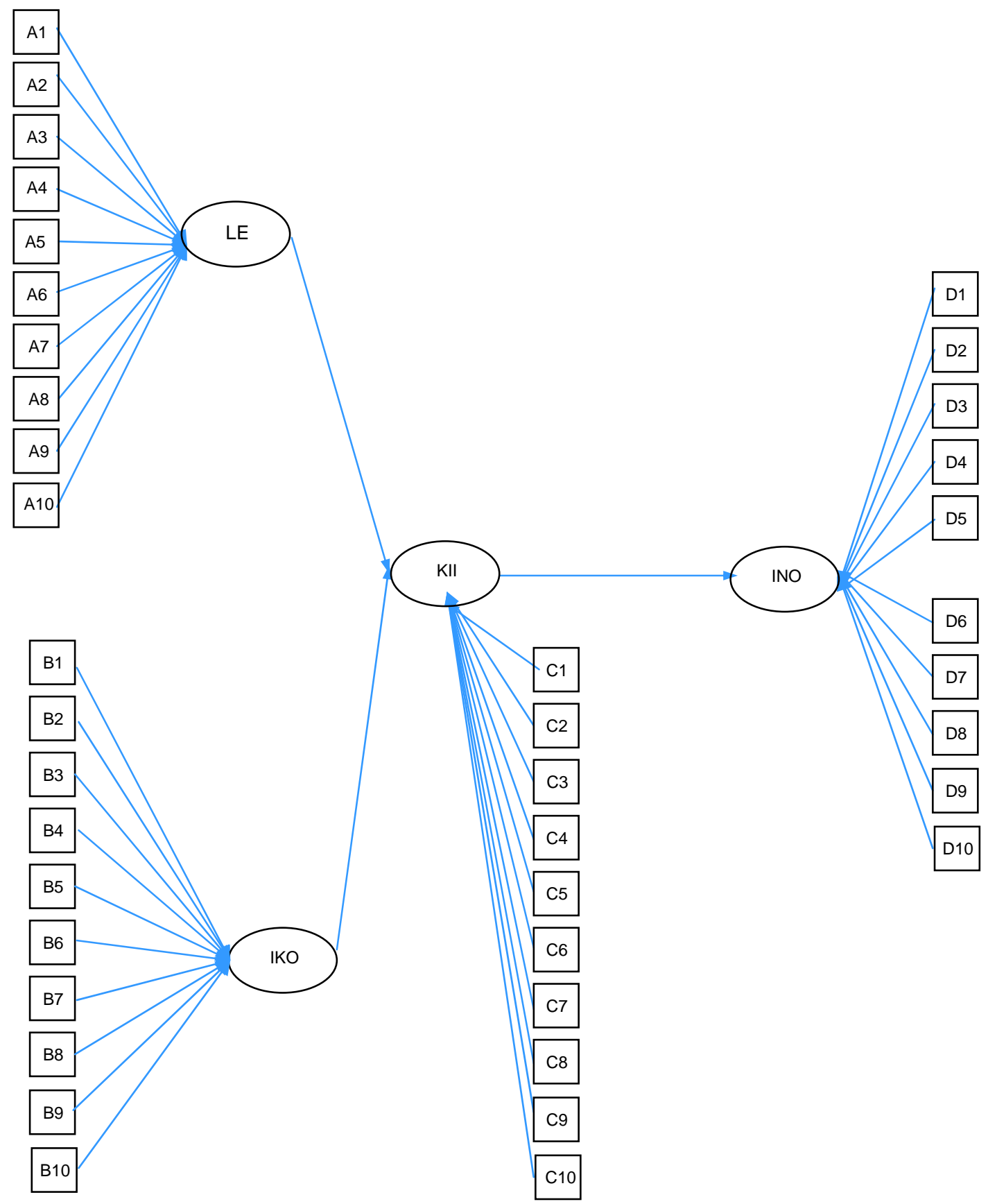

Sumber: Hasil Pengolahan Data (2007)

Gambar 4 Path Diagram Awal 


\section{Hasil Akhir Penilaian Model FIT}

Dari output Completely Standarized Solution:

Completely Standardized Solution

$$
\text { LAMBDA - X1 }
$$

LINGKUNGAN EKSTERNAL

$\begin{array}{ll}\text { A2 } & 0,589 \\ \text { A3 } & 0,689 \\ \text { A4 } & 0,617 \\ \text { A5 } & 0,700 \\ \text { A7 } & 0,785 \\ \text { A9 } & 0,885\end{array}$

GAMMA

LINGKUNGAN EXSTERNAL

INTELEKTUAL INDIVIDU

LAMBDA - X2

IKLIM ORGANISASI

B1 0,522

B2 0,504

B3 0,681

B4 $\quad 0,669$

B5 $\quad 0,572$

B7 $\quad 0,575$

B8 0,669

B10 0,569

GAMMA

IKLIM ORGANISASI

INTELEKTUAL INDIVIDU

$\mathbf{0 , 6} \mathbf{6} \mathbf{1}$ 


\begin{tabular}{cc}
\multicolumn{2}{l}{ LAMBDA - Y3 } \\
\\
C2 & 0,496 \\
C3 & 0,696 \\
C4 & 0,685 \\
C5 & 0,785 \\
C6 & 0,800 \\
C10 & 0,532 \\
LAMBDA - Y4 \\
\\
\\
D1 & INTELEKTUAL ORGANISASI \\
D3 & 0,727 \\
D7 & 0,632 \\
D8 & 0,682 \\
D9 & 0,522 \\
D10 & 0,617 \\
& 0,687 \\
GAMMA & \\
& \\
INTELEKTUAL INDIVIDU & $\mathbf{0 , 6 0 9}$
\end{tabular}




\section{Hasil Akhir Model Konstruk Penelitian}

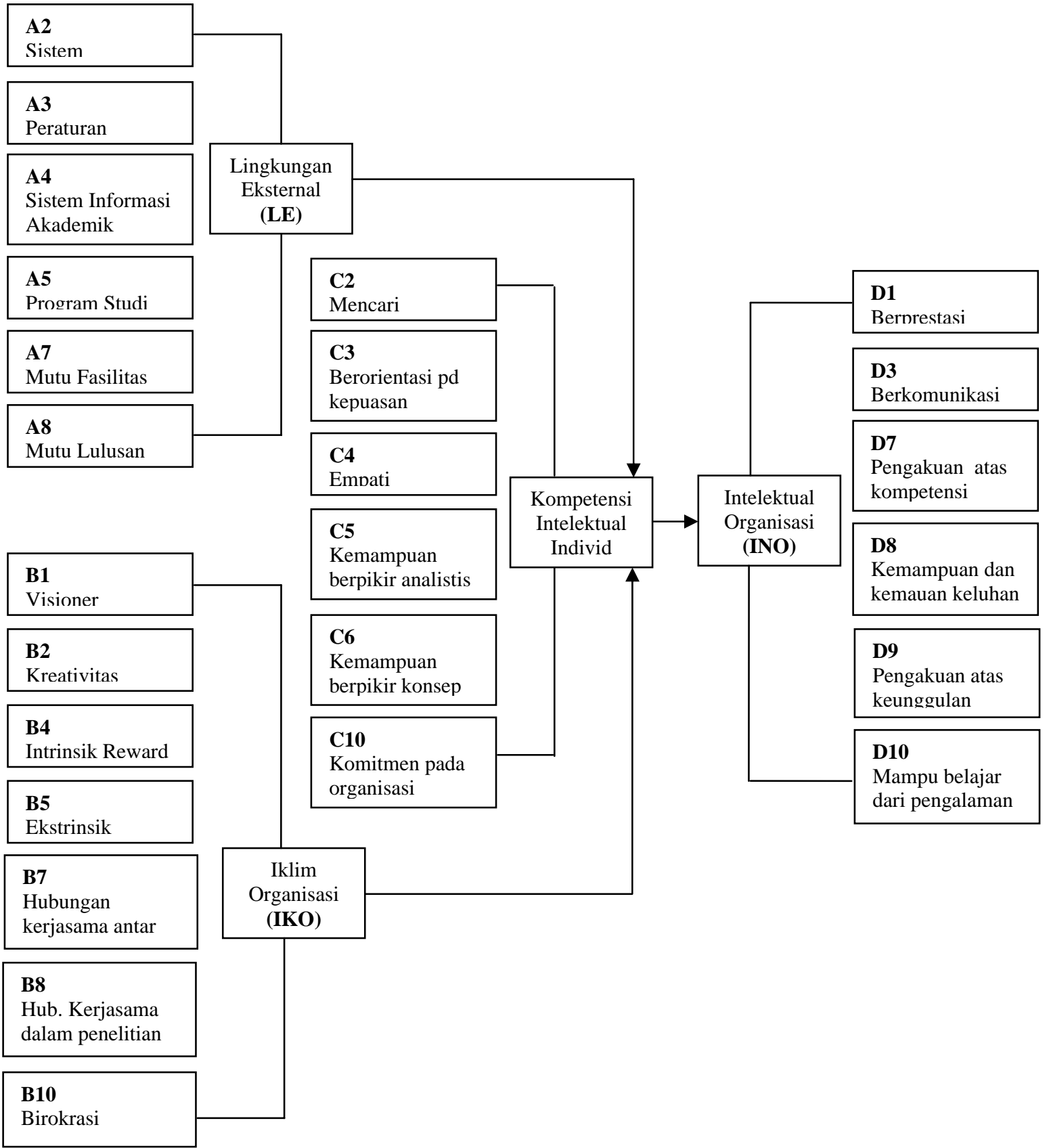

Sumber : Hasil Pengolahan data (2007)

Gambar 5 Model Konstruk Final Hubungan LE, IKO terhadap KII dan INO 


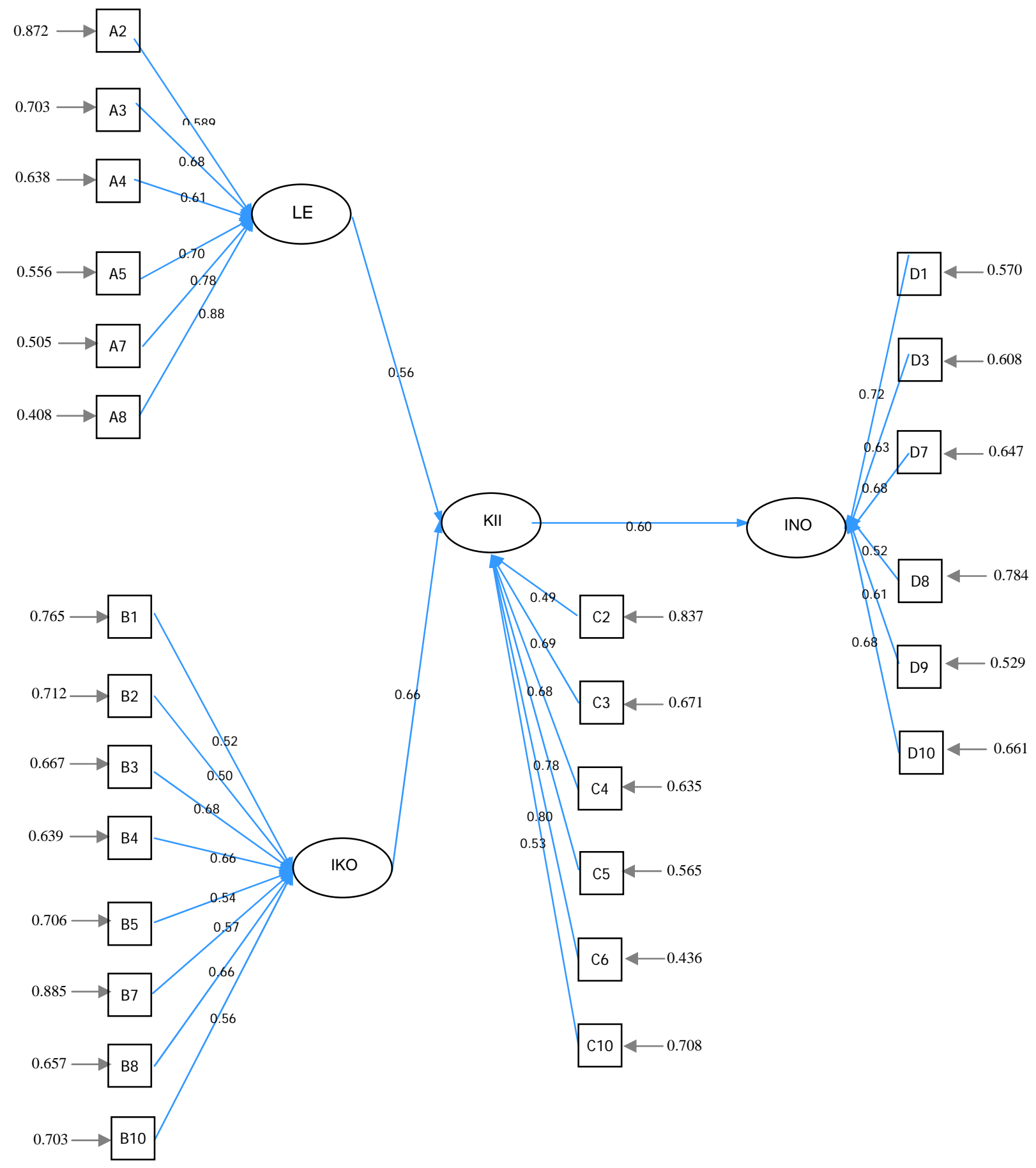

Sumber: Hasil Pengolahan Data (2007)

Gambar 6 Output Path Diagram FIT 


\section{Keterangan Hubungan antarVariabel}

Variabel tersebut, baik variable Measured (latent) maupun Observed (indicator), merupakan variabel yang paling optimal sehingga membentuk model yang fit sesuai gambar Path Output tersebut karena nilai masing-masing variabel yang $>\mathbf{0 . 0 5}$. Berikut adalah penjelasan hubungan antarvariabel.

\section{LE (Lingkungan Eksternal}

- Indikator A2 dapat menjelaskan variabel eksogennya LE (Lingkungan Eksternal) sebesar 0.589 atau sebesar 58,9\%, dan $41,1 \%$ dijelaskan oleh variabel selain A2 dengan tingkat kesalahan $87,2 \%$.

- Indikator A3, A4, A5, A7 dan A8, cara membacanya sama dengan cara membaca Indikator A2.

\section{IKO (Iklim Organisasi)}

- Indikator B1 dapat menjelaskan variabel eksogennya IKO (Iklim Organisasi) sebesar 0.522 atau sebesar 52,2\%, dan 47,8\% dijelaskan oleh variabel selain B1 dengan tingkat kesalahan $76,5 \%$.

- Indikator B2, B3, B4, B5, B7, B8 dan B10 cara membacanya sama dengan cara membaca Indikator B1.

\section{KII (Kompetensi Intelektual Individu)}

- Indikator C2 dapat menjelaskan variable interveningnya KII (Kompetensi Intelektual Individu) sebesar 0.496 atau sebesar $49,6 \%$, dan 51,4\% dijelaskan oleh variabel selain C2 dengan tingkat kesalahan 83,7\%.

- Indikator C3, C4, C5, C6, dan C10, cara membacanya sama dengan cara membaca Indikator C2.

\section{Nilai Optimal (A) dan (B)}

- Nilai optimal dari keseluruhan indicator A terhadap LE yang mempengaruhi KII sebesar 0.565 .

- Nilai Optimal dari keseluruhan indicator B terhadap IKO yang mempengaruhi KII sebesar 0.661 .

\section{INO (Intelektual Organisasi)}

- Indikator D1 dapat menjelaskan variable endogennya INO (Intelektual Organisasi) sebesar 0.727 atau sebesar $72,7 \%$, dan $27,3 \%$ dijelaskan oleh variabel selain D1 dengan tingkat kesalahan 57,0\%.

- Indikator D3, D7, D8, D9, dan D10, cara membacanya sama dengan cara membaca indikator D1. 


\section{Analisis Hasil Penelitian}

\section{Nilai Optimal keseluruhan}

- Nilai Optimal dari keseluruhan indicator C serta Variabel LE dan IKO terhadap KII yang mempengaruhi INO sebesar 0.609

\section{Simpulan}

- Tidak ada hubungan langsung antarindikator, baik dalam satu variabel maupun antar variabel.

- Masing-masing indikator mempengaruhi secara langsung setiap variabel latentnya.

- Mulai dari variabel latent KII, selain dipengaruhi oleh indikatornya juga dipengaruhi oleh Varibel latent sebelumnya, yakni, LE, dan IKO. Demikian juga pada Variabel INO.

- Berarti, variabel eksogen LE memiliki pengaruh sebesar 0.565 atau 56.5\% terhadap variabel intervening KII, variable eksogen IKO sebesar 0.661 atau 66.1\% terhadap Variabel Intervaning KII, dan variabel Intervaning KII memiliki pengaruh sebesar 0.609 atau $60.9 \%$ terhadap variabel endogen INO. Atau dengan kata lain yang diterima adalah HO: Lingkungan Eksternal dan Iklim Organisasi berpengaruh terhadap Kompetensi Intelektual Individu dan Modal Intelektual Organisasi.

\section{Validasi Konstruk}

Model konstruk penelitian yang sudah disusun sebelumnya perlu diuji validitasnya menggunakan software lisrel 8.30. Koefisien model persamaan struktur yang diperoleh merupakan koefisien validitas konstruk variabel yang diukur (joreskog dan Sorbon, 1993). Hasil pengukuran model persamaan strukturnya, seperti dijelaskan dalam Tabel 4.

Tabel 4 Hasil Pengukuran Model Persamaan Struktural Variabel Kompetensi Intelektual Individu (KII)

\begin{tabular}{clcccc}
\hline No. & Persamaan Struktural & Variasi kesalahan & $\mathbf{R}^{2}$ & Simpangan Baku & Nilai T (1,96) \\
\hline 1 & C2 $=0.496 * \mathrm{C}$ & 0.837 & 0.13 & 0.13 & 2.95 \\
2 & C3 $=0.696 * \mathrm{C}$ & 0.671 & 0.14 & 0.14 & 3.24 \\
3 & C4 $=0.685 * \mathrm{C}$ & 0.635 & 0.14 & 0.14 & 3.08 \\
4 & C5 $=0.785^{*} \mathrm{C}$ & 0.565 & 0.10 & 0.10 & 4.32 \\
5 & C6 $=0.800 * \mathrm{C}$ & 0.436 & 0.084 & 0.084 & 3.04 \\
6 & C10 $=0.532 * \mathrm{C}$ & 0.708 & 0.089 & 0.089 & 5.27 \\
\hline
\end{tabular}

Sumber: Hasil Pengolahan Data (2007)

\section{Variabel Kompetensi Intelektual Individu (KII)}

Tabel 4 adalah hasil pengukuran model persamaan strukturan variabel Kompetensi Intelektual Individu (KII). Dari tabel tersebut dapat diambil simpulan sebagai 
berikut. Pertama, tidak terdapat satu variabel manifes yang memiliki nilai t (perbandingan antara estimasi dan standar kesalahan, Joreskog dan Sorbom, 1993) lebih kecil dari 1,96. Hal itu berarti bahwa hampir semua variabel manifes tersebut memiliki pengaruh yang signifikan terhadap variabel laten. Kedua, tidak terdapat variabel yang memiliki bobot faktor lebih kecil daripada 0,3. Hal itu berarti semua variabel manifes memiliki pengaruh yang sigifikan terhadap variabel laten.

Ketiga, variabel manifes C2: (pernyataan tentang Dalam membuat keputusan, saya biasa melakukan cukup berani setelah saya mengetahui permasalahannya terlebih dahulu) memiliki bobot paling rendah. Oleh karena itu, apabila ingin meningkatkan kompetensi intelektual individu dosen, perlu diusahakan agar program dimasa yang akan datang perlu difokuskan pada variabel manifes yang memiliki bobot faktor relatif rendah, yaitu dengan memberikan motivasi lebih kepada para dosen untuk berani mengambil risiko terhadap apa yang menjadi beban dan tanggung jawabnya, mungkin dengan lebih banyak bicara dari hati ke hati.

Keempat, bobot paling tinggi dihasilkan oleh variabel manifes C6 (pernyataan tentang Universitas kami selalu menyediakan dosen dan karyawan untuk mengikuti pendidikan dan pelatihan secara merata). Hal itu berarti bahwa kemampuan berfikir konsep atau kemampuan kognitif merupakan indikator yang paling dominan untuk mewujudkan kompetensi intelktual individu (Tabel 5).

Tabel 5 Hasil Pengukuran Model Persamaan Struktural Variabel Modal Intelektual Organisasi (INO)

\begin{tabular}{clrrrc}
\hline No. & Persamaan Struktural & $\begin{array}{c}\text { Variasi } \\
\text { kesalahan }\end{array}$ & \multicolumn{1}{c}{$\mathbf{R}^{2}$} & $\begin{array}{c}\text { Simpangan } \\
\text { Baku }\end{array}$ & $\begin{array}{c}\text { Nilai T } \\
(\mathbf{1 , 9 6 )}\end{array}$ \\
\hline 1 & D1 $=0.727 * \mathrm{D}$ & 0.570 & 0.51 & 0.062 & 8.32 \\
2 & D3 $=0.632 * \mathrm{D}$ & 0.608 & 0.44 & 0.077 & 6.70 \\
3 & D7 $=0.682 * \mathrm{D}$ & 0.647 & 0.28 & 0.075 & 9.43 \\
4 & D8 $=0.522 * \mathrm{D}$ & 0.784 & 0.560 & 0.075 & 9.06 \\
5 & D9 $=0.617 * \mathrm{D}$ & 0.529 & 0.52 & 0.087 & 5.88 \\
6 & D10 $=0.687 * \mathrm{D}$ & 0.661 & 0.22 & 0.065 & 9.34 \\
\hline
\end{tabular}

Sumber: Hasil Pengolahan Data (2007)

\section{Variabel Modal Intelektual Organisasi (INO)}

Tabel 5 adalah hasil pengukuran model persamaan strukturan variabel Modal Intelektual Organisasi (INO). Dari tabel tersebut dapat diambil simpulan sebagai berikut. Pertama, tidak terdapat satu variabel manifes yang memiliki nilai $\mathbf{t}$ (perbandingan antara estimasi dan standar kesalahan, Joreskog dan Sorbom, 1993) lebih kecil dari 1,96. Hal itu berarti bahwa hampir semua variabel manifes tersebut memiliki pengaruh yang signifikan terhadap variabel latennya. Kedua, tidak terdapat variabel yang memiliki bobot faktor lebih kecil daripada 0,3. Hal itu berarti semua variabel manifes memiliki pengaruh yang sigifikan terhadap variabel laten. 
Ketiga, variabel manifes D8: (pernyataan tentang Keluhan yang datang dari para pengguna jasa selalu ditanggapi dengan sungguh-sungguh oleh Universitas kami) memiliki bobot paling rendah. Oleh karena itu, apabila ingin meningkatkan intelektual Organisasi perlu diusahakan agar program di masa yang akan datang perlu difokuskan pada variabel manifes yang memiliki bobot faktor relatif rendah, yaitu dengan menanggapi setiap keluhan sekecil apapun dengan memberikan jawaban langsung ataupun tidak langsung secepat mungkin sehingga pengguna jasa dapat merasa seperti memiliki universitas.

Keempat, bobot paling tinggi dihasilkan oleh variabel manifes D1 (pernyataan tentang Teman-teman dosen selalu berusaha dengan sungguh-sungguh menyelesaikan tugas penting yang menjadi tanggung jawabnya dalam meningkatkan mutu pendidikan). Hal itu berarti bahwa teman dosen sudah mempunyai tanggung jawab pribadi untuk menyelesaikan suatu pekerjaan sebagai pendidik yang dibebankan. Komitmen sebagai dosen secara pribadi sudah berjalan di Universitas kami, mengingat pekerjaan pendidik (dosen) sudah dapat menjadi pegangan hidup sebagai mata pencaharian.

\section{PENUTUP}

Dari hasil penelitian, didapat beberapa simpulan yang dapat digunakan sebagai referensi dari penelitian ini sebagai berikut. Pertama, model yang diajukan pada penelitian ini adalah TIDAK FIT (close-fit) namun kemudian dikoreksi menuju model yang paling FIT $(>0,8)$ good-fit. Kedua, terdapat $\mathbf{2}$ modifikasi yang dilakukan untuk memperoleh model yang paling FIT. Ketiga, hipotesis diterima, namun terdapat hubungan kualitas (pengaruh dan positip), signifikan, dan reliabel antara lingkungan eksternal dan iklim organisasi terhadap intelektual individu dan modal intelektual organisasi. Keempat, terbentuknya beberapa hubungan korelasi positip pada beberapa indikator sebagai nilai yang tersembunyi untuk menjelaskan tercapainya model yang FIT.

\section{DAFTAR PUSTAKA}

Argyris, C. 1992. On organizational Learning. Cambridge: Blackwell Publisher, Inc.

Cohen, L. and L. Manion. 1997. Research Methods in Education. $4^{\text {th }}$ Ed. London: Routledge.

Departemen Pendidikan Nasional. 2003. Undang-Undang Republik Indonesia Nomor 20 Tahun 2003 Tentang Sistem Pendidikan Nasional. Jakarta: Depdiknas.

De Geus, Arie. 1998. “Planning as Learning,” Harvard Business Review, Vol 88, No. 2. 
Fattah, N. 2000. Manajemen Berbasis Sekolah. Bandung: Andira.

Garvin, D.A. 1998. "Building a Learning Organization," Harvard Business Review on Knowledge Management. Boston: Harvard Business School Press.

Hicks, H.B. and C.R. Gullet. 1976. The Management of Organization. $3^{\text {rd }}$ Ed. New York: McGraw-Hill.

Joyce, B., M. Weil, and B.Showers. 1992. Models of Teaching. 4th Ed. Boston: Allyn and Bacon.

Kolb, David A, Irwin M. Rubin, dan James M. McIntyre. 1991. Organizational Psychology; An Experiential Approach. USA: Prentice Hall.

Kuncoro, Mudrajad. 2003. Metode Riset untuk Bisnis dan Ekonomi. Jakarta: Erlangga.

Lewis, R.G., and D.H. Smith. 1997. Total Quality in Higher Education. Florida: St. Lucie Press.

Lunenburg, F.C. and A.C. Ornstein. 1991. Educational Administration, Concepts, and Practises. Belmont: Wadsworth Publishing Company.

Marquardt, M.J. 1996. Building the Learning Organzation. New York: McGraw-Hil.

Moedjadi. 2005. Pengaruh Persaingan dan Organisasi Belajar (Learning Organization) terhadap Proses Transformasi Kompetensi Intelektual Individu Menjadi Modal Intelektual Organisasi. UPI: Bandung.

Nawawi, H. 1997. Admnistrasi Pendidikan. Cetakan ke-14. Jakarta: Gunung Agung.

Ramsden, P. 2003. Learning to Teach in Higher Education. $2^{\text {nd }}$ Ed. London: Routledge Falmer.

Riduwan dan Engkos Achmad Kuncoro. 2006. Analisis Jalur (Path Analysis). Bandung: Alfabeta.

Stoner, James A.E and Edward Freeman. 1996. Management. New York: Prentice Hall Inc.

Spenser, Lyle M. Jr. dan Spencer Signe M. 1993. Competence at Work, Models For Superior Performance. New York: John Willey \& Soon, Inc.

Santoso, Singgih. 2001. SPSS Versi 10, Mengolah Data Statistik Secara Profesional. Jakarta: Elex Media Komputindo. 